\title{
Sonlu Elemanlar Stres Analizi ve Endodontide Kullanımı
}

\author{
Finite Element Stress Analysis and Its Use in Endodontics
}

\author{
Merve AKBAȘ ${ }^{1} \oplus$, Makbule Bilge AKBULUT ${ }^{2} \oplus$, Sema BELLI $^{3}$
}

Öz

Sonlu elemanlar stres analizi yöntemi, karmaşık yapıları modellemek ve oluşturulan modeller üzerinde stres analizini belirlemek için sıklıkla kullanılan bir yöntemdir. Sonlu elemanlar stres analizi, uzun zamandır mühendislik alanında kullanılırken 1970'li yıllardan bu yana da diş dokularını temsil eden modellere uygulanmaktadır. Sonlu elemanlar stres analizi daha spesifik olarak endodonti alanında; giriş kavitesi açılması, kök kanal preparasyonu ve kök kanal dolumu esnasında dişlerin biyomekanik davranışının incelenmesinde, endodontik tedavi sonrası restoratif prosedürlerin değerlendirilmesinde sıklıkla kullanılmıştır. Bu derlemenin amacı sonlu elemanlar stres analizi ve bu yöntemin endodonti alanındaki uygulamaları konusunda güncel ve kapsamlı bilgi vermektir.

Anahtar Kelimeler: Sonlu elemanlar analizi, Endodonti, Kök kanal tedavisi, Vertikal kök kırığ1

\begin{abstract}
Finite element stress analysis is a method that is frequently used to model complex structures and determine stress analysis on created models. While finite element stress analysis has been used in the field of engineering for a long time, it has been applied to models representing dental tissues since the 1970s. Finite element stress analysis has been used more specifically in the field of endodontics; for investigating biomechanical behavior of teeth during access cavity preparation, root canal preparation and root
\end{abstract}

Merve Akbaş (凶)

Araştırma Görevlisi, Endodonti AD, Necmettin Erbakan Üniversitesi Diş Hekimliği Fakültesi, Konya, Türkiye.

e-mail:dtmervee@gmail.com

Makbule Bilge Akbulut

Doçent Dr, Endodonti AD, Necmettin Erbakan Üniversitesi Diş Hekimliği

Fakültesi, Konya, Türkiye.

Sema Belli

Profesör Dr, Endodonti AD, Selçuk Üniversitesi Diş Hekimliği Fakültesi, Konya, Türkiye.

Submitted / Gönderilme: 07.06.2021

Accepted/Kabul: 09.09.2021 canal filling, and in the evaluation of restorative procedures after endodontic treatment. The objective of this review is to provide current and comprehensive information about finite element stress analysis and its applications in endodontics.

Keywords: Endodontics, Root Canal Therapy, Finite element analysis, Vertical root fracture

\section{Diş Hekimliğinde Kullanılan Stres Analiz Yöntemleri}

Diş hekimliğinde kullanılan materyallerin mekanik özelliklerini ve kuvvet karşısındaki streslerini bilmek başarılı bir tedavi için çok önemlidir (Craig ve Powers 2002). Canlı dokuların ve organların kuvvet karşısında nasıl davrandığını ve stres analizini belirlemek zor, pahalı, riskli ve hatta bazen imkânsız olabilir (Magne 2007). Bu nedenle, canlı dokuları temsil eden modellerde stres analizi çalışmalarının yapılması gerekebilir. Bir nesne üzerindeki kuvvetlerin yoğunlaştığ 1 bölgeleri görmek ve nesneyi gelebilecek kuvvetlere karşı daha güçlü ve daha dayanıklı hale getirmek ve bu amaçla ideal tasarımın ne olması gerektiğini belirlemek için çeşitli stres analizi yöntemleri kullanılmaktadır (Çalıkoğlu 1992).

Klasik matematiksel stres analizi yöntemleri, kapsamları açısından son derece sınırlıdır ve düzensiz yapısal forma sahip olan ve kompleks yüklere maruz kalan diş yapıları için uygun değildir (Verdonschot ve ark. 2001). Ancak sonlu elemanlar stres analizi (Finite element analysis, FEA) yöntemi, düzensiz geometri ve heterojen malzeme özelliklerinin katılara uygulanabilme avantajına sahip modern bir sayısal stres analizi tekniğidir. Bu nedenle ağız boşluğunun yapısal davranışının incelenmesi için ideal özelliklere sahiptir (Desai ve Shinde 2012). 


\section{FEA Tarihçesi, FEA nedir?}

FEA bir materyalin veya modelin belirli materyal özellikleri için yapay olarak strese girmesini veya analiz edilmesini bilgisayar yardımıyla sağlayan bir metottur (Hammond ve Whitty 2015). Başlangıçta bu teknik yalnızca mühendislik alanında yaygın olarak kullanılırken (Thresher ve Saito 1973), 1970'li yıllardan bu yana diş hekimliğinde de uygulanmaya başlamıştır (Farah ve Craig 1974). Sonlu elemanlar stres analizi, dental sistemlerde meydana gelen stres dağılımlarının karmaşık koşullarını belirlemek için şu anda mevcut olan en kapsamlı yöntem olarak bilinmektedir (Versluis ve Tantbirojn 2009). Sonlu elemanlar analizinin avantaj ve dezavantajları Tablo 1'de gösterilmektedir.

Tablo 1. Sonlu elemanlar analizinin avantaj ve dezavantajları

\begin{tabular}{|l|l|}
\hline \multicolumn{1}{|c|}{ AVANTAJ } & \multicolumn{1}{c|}{ DEZAVANTAJ } \\
\hline -Etik hususlar yoktur & -Analizin yürütülebilmesi için çoğu \\
(Huempfner-Hierl ve ark. & zaman uzman kişilerden destek alınması \\
2014). & gerekir (Shetty ve ark. 2010). \\
-Deneyler kolaylıkla & -Klinik durumun tamamen \\
tekrarlanabilir ve çalışma & tekrarlanamayabileceği bilgisayar \\
tasarımları gereksinime & yardımıyla yapılan bir in vitro çalışmadır \\
göre modifiye edilip & (Saxena ve Chandak 2016). \\
değiştirilebilir (Huempfner- & -Deneysel analizlerin yerine tek başına \\
Hierl ve ark. 2014). & kullanılmamalı, deneysel yöntemlerle \\
-Deneysel çalışmalarla elde & desteklenmelidir (Soares ve ark. 2012). \\
edilemeyen bilgiler sağlar & -FEA ile elde edilen sonucun güvenilir \\
(Soares ve ark. 2012). & olması için oluşturulan modelin gerçeğe \\
-Karmaşık yapılar & yakın olması gerekmektedir. \\
modellenip, incelenebilir & - Stres analizi çalışmalarını yapmak için \\
(Gokhale ve ark. 2008). & FEA kullanıldığında mevcut modelin \\
-Düşük işletme maliyeti & izotropik, homojen ve lineer elastik \\
vardır (Soares ve ark. 2012). & olduğu varsayllır ve bu durum gerçeği \\
-Araştırmanın yürütülmesi & yansıtmamaktadır (Hu ve ark. 2010). \\
için daha az zaman & Örneğin bir dentin modelinde, dentinin \\
gerektirir (Soares ve ark. & tübüler yapısı göz ardı edilmektedir. \\
2012). & -Kullanılan ticari yazılım programları, \\
- Medikal alanda ve diş & kapsam yeteneklerine bağlı olarak \\
hekimliği alanında kişiye & pahalıdır (Shetty ve ark. 2010). \\
özel stres analizi yapılabilir & -Önemli miktarda bilgisayar ve kullanıcı \\
(Magne 2007). & süresi gerektirir (Desai ve Shinde 2012). \\
\hline
\end{tabular}

\section{Sonlu Elemanlar Analizinde Kullanılan Temel Mekanik Kavramlar}

\section{A. Kuvvet}

Nesnelerin hareketini ve şeklini değiştirebilecek etki kuvvet olarak tanımlanmaktadır (Aktı ve Kaya 2020). Bir kuvvetin yönü, kuvvet türünün özelliğidir. Uluslararası Birimler Sistemi (SI) kuvvet birimi Newton'dur (N) (Sakaguchi ve Powers 2012).

\section{B. Gerilme (stres)}

Bir kuvvet bir cisme etki ettiğinde, bu kuvvete cisim tarafından karşı koyulur. Bu iç reaksiyon, uygulanan dış kuvvete büyüklük bakımından eşit ve ters yöndedir ve gerilme (stres) olarak adlandırılır, tipik olarak $\mathrm{S}$ veya $\sigma$ ile gösterilir. Gerilim birimi, kuvvet biriminin $(\mathrm{N})$ bir alan birimine bölünmesidir ve genel olarak SI birimlerinde Pascal $(1 \mathrm{~Pa}=1 \mathrm{~N} / \mathrm{m}-=1 \mathrm{MN} / \mathrm{mm}-)$ olarak ifade edilir (Sakaguchi ve Powers 2012).

Uygulanan kuvvete bağl olarak 3 tip gerilme (stres) vardır (şekil 1): (Sakaguchi ve Powers 2012)

- Sikışma Gerilmesi (Compressive Stress): Bir cismi sıkıştırmaya veya kısaltmaya çalışan, aynı doğrultuda ve farklı yönde iki kuvvetin oluşturduğu gerilmeye sıkışma gerilmesi adı verilmektedir.

- Çekme Gerilmesi (Tension stress): Aynı doğrultuda ancak zıt yöndeki iki kuvvet tarafından oluşturulan, nesneleri germek veya esnetmek isteyen kuvvetlerin oluşturduğu gerilim türüdür.

- Kesme "Makaslama" Gerilmesi (Shear Stress): Farkl1 düzlemde ve zit yöndeki paralel iki kuvvetin cisim üzerinde etki ettiği bölgeyi zıt yönde kaymaya zorlayan gerilim türüdür.

Şekil 1. Kuvvet uygulanması sonucunda cisimde meydana gelen gerilme tipleri
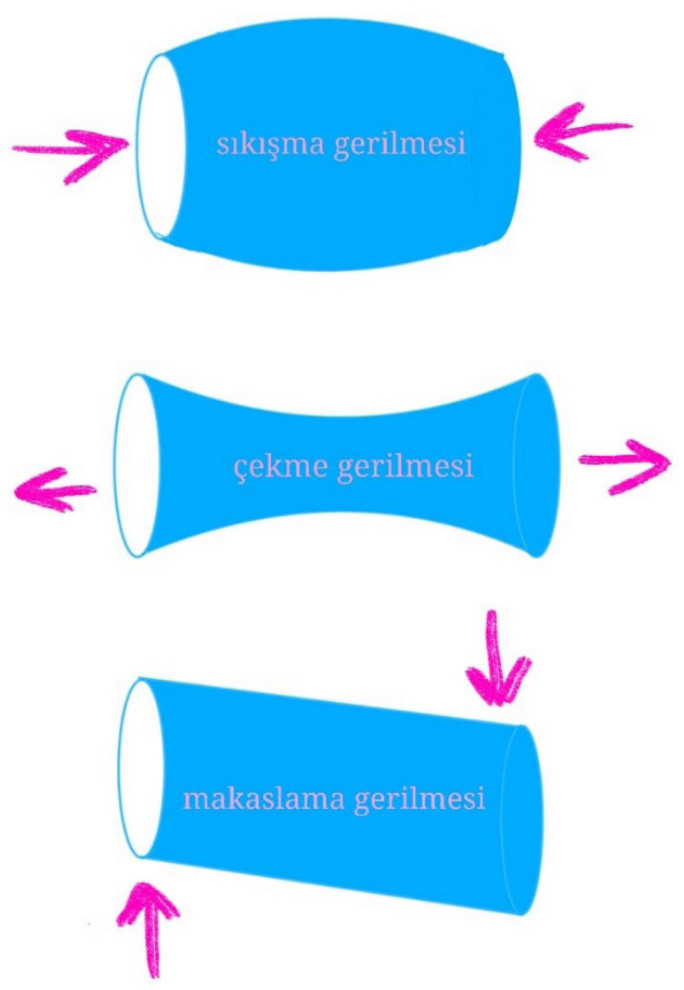


\section{Gerinim (strain)}

Bir nesneye uygulanan kuvvetin etkisiyle meydana gelen boyutsal değişimin, nesnenin orijinal boyutuna oranına 'gerinim' adı verilmektedir ve "Gerinim = Boyuttaki Değişim / İlk Boyut" şeklinde hesaplanmaktadır. Şekil değiştirme genellikle yüzde (\%) olarak ifade edilir (Fung 2013).

\section{Temel Stres (Principal Stress)}

Mevcut gerilmelerin sadece dik olarak hareket ettiği ve kayma gerilmesinin herhangi bir düzlemde etkilemediği gerilmelere 'temel stres' denir (Marghitu 2001; Sung ve ark. 2003).

\section{E. Esneklik Modülü (Young Modülü)}

Bir malzemenin esneklik ölçüsü, aynı zamanda elastisite modülü veya Young modülü olarak da adlandırılır. Esneklik modülü, elastik aralık içindeki bir malzemenin sertliğini temsil eder. Esneklik modülü, gerilmenin gerinime oranı veya eğrinin doğrusal bölgesinin eğimi hesaplanarak bir gerilme-gerinim eğrisinden belirlenebilir. Modülüs aşağıdaki denklemden hesaplanır:

Elastik modül $=$ Gerilme $/$ Gerinim

Bu denklem aynı zamanda Hooke kanunu olarak da bilinir. Gerinim birimsiz olduğu için, modül gerilim ile aynı birimlere sahiptir ve genellikle MPa veya GPa (1 GPa $=1000 \mathrm{MPa}$ ) cinsinden rapor edilir (Sakaguchi ve Powers 2012).

\section{F. Poisson Oranı}

Elastik aralık içinde, endeki birim uzamanın, boyundaki birim uzamaya olan oranı Poisson oranı olarak adlandırılır. Poisson oranı birimsiz bir değerdir çünkü iki strain (gerinim) oranıdır (Sakaguchi ve Powers 2012).

\section{G. Von Mises Stresi}

Von Mises Stresi, esneyebilen materyaller için kullanılır ve şekil değiştirmenin başlangıcı olarak tanımlanır (Küçükkurt 2019).

\section{H. Hook Yasasl}

Gerilim ve gerinim arasındaki doğrusal ilişkiyi kabul eden bir yasadır. Belirli stres sınırlarını aşmamak koşuluyla, nesnelerin davranışlarını yaklaşık olarak ifade eder. Hook yasası rijit malzemelerin yüksek elastikiyet katsayısına sahip olduğunu gösterirken, esnek malzemelerin düşük elastikiyet katsayısına sahip olduğunu göstermektedir (Rho ve ark. 1993).

\section{Yorulma Dayanımı (Akma Dayanımı-Yield Stress)}

Maksimum direnci aşılan malzeme kırılır, yani plastik deformasyona maruz kalır. Elastik ve plastik deformasyon arasındaki sınıra yorulma direnci denir. Akma noktasına kadar, nesne elastik deformasyondadır ve gerilme kaybolursa eski haline getirilebilir (Fung 2013). Başarısızlık noktasına kadar artan çekme gerilmesine maruz kalan bir materyal için bir gerilme-gerinim eğrisi Şekil 2'de gösterilmektedir.

Şekil 2. Gerilme-gerinim eğrisi

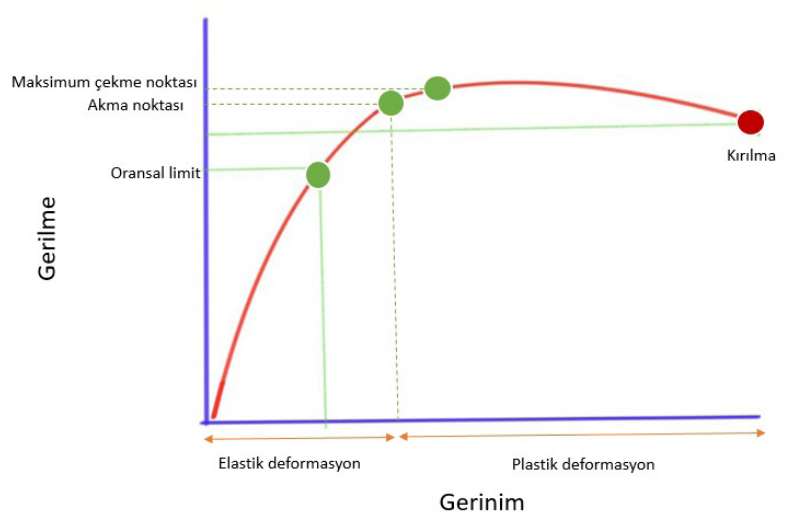

Uygulama aşamaları-Sonlu elemanlar analizi nasıl çalışır?

FEA kullanarak yapılan çözüm prosedürü adımları

1.İşlem öncesi aşaması (pre-processing)

2.İşleme aşaması (processing)

3.İşlem sonrası aşaması (post-processing)

\section{1.İşlem öncesi aşaması (pre-processing)}

\section{Geometrik modelin oluşturulması}

İlk adım, analiz için yapının geometrik modelini oluşturmaktır (Gao ve ark. 2006). FEA'da modellerin oluşturulması genellikle zordur, çünkü biyolojik yapılar 
karmaşık şekillere sahiptir, farklı malzemelerden ve / veya kompozisyonlardan oluşur ve yükleme koşulları sonuçların doğruluğunu etkileyebilir. Bu nedenle, FEA'dan doğru sonuçlar elde etmek için bir modelin doğru şekilde oluşturulması çok önemlidir. 2D ( 2 boyutlu) modeller için, modelleme bir yapının (fotoğraf, tomografi veya radyografi) görüntülerden veya düzlemsel bölümlerinden yapılır. Sonlu elemanlar yönteminde biyolojik yapıların modellenmesi genellikle CAD (Computer Aided Design) yazılımları vasıtasıyla gerçekleştirilir (Soares ve ark. 2012).

\section{A $\breve{g}$ oluşturma}

Model oluşturulduktan sonra ayrıştırma (discretization) işlemi yani problemi düğümlerle bağlantılı birkaç küçük öğeye bölme işlemi gerçekleştirilir (Saxena ve Chandak 2016). FEA, ağ olarak adlandırılan ızgara yapan karmaşık bir nokta sistemi (düğümler) ve elemanlar kullanır (Desai ve Shinde 2012). Elemanların birbirine bağlandığı noktalara 'düğüm' denir ve tüm yapı 'ağ (mesh)' olarak adlandırılır (Aktı ve Kaya 2020). Elemanların düğümlerle birleştirilmesi ve yinelenen düğümlerin ortadan kaldırılması "ağ oluşturma" olarak adlandırılır. Elemanlar oluşturulurken elemanların çakışmamasına, yalnızca düğümler olarak adlandırılan kilit noktalarda bağlanmasına dikkat edilmelidir (Saxena ve Chandak 2016). Ayrıca elemanların yapısı mümkün olduğunca basit olmalıdır (Aktı ve Kaya 2020).

Düğümler malzeme boyunca değişen bir yoğunlukta yerleştirilir. $\mathrm{Bu}$, belirli bir alandaki stres veya zorlanma miktarına bağlıdır. Çok fazla strese maruz kalabilecek alanlar, stres olmayan alanlardan daha fazla düğüm yoğunluğuna sahiptir (Hammond ve Whitty 2015). Dügüm sayısı ne kadar fazla olursa, analizden elde edilecek sonuçlar gerçek sonuçlara o kadar yakın olur (De Vree ve ark. 1983).

Çoğu FEA yazılımı otomatik ya da manuel ağ oluşturma seçeneğine sahiptir. FEA programları, model oluşturulmasında kullanılacak olan elemanların boyutunu ve sayısını önerebilir veya manuel olarak kontrol edilmesine izin verebilir. Manuel ağ oluşturma, 2 boyutlu modeller için iyi sonuçlar verebilmesine rağmen 3D (3 boyutlu) modellerin çoğu otomatik ağ üreticilerine dayanır, çünkü 3D modellerin manuel olarak oluşturulması çok zaman alır (Soares ve ark. 2012).

\section{İki boyutlu ve üç boyutlu modelleme}

Genel olarak FEA' da yapılan analiz 2 boyutlu modelleme ve 3 boyutlu modelleme kullanılarak gerçekleştirilebilir (Srirekha ve Bashetty 2010). Bu iki modelden hangisinin seçileceği, geometrinin karmaşıklı̆̆ı, malzeme özellikleri, analiz şekli, genel bulguların uygulanabilirliği ve zaman ve maliyet gibi birbiriyle ilişkili birçok faktöre bağlıdır (Romeed ve ark. 2004; Poiate ve ark. 2011). İki boyutlu modelleme için üçgen ve dörtgen şekilli elemanlar tercih edilirken üç boyutlu modellerde dört, beş ve altı yüzlü elemanlar tercih edilmektedir (Gokhale ve ark. 2008). Ana model ne kadar gerçeğe yakın olursa FEA ile o kadar güvenilir sonuçlar elde edilir. Diş hekimliği alanında da gerçeğe yakın modeller elde etmek için dişlerin bilgisayarlı tomografi ile taranmış görüntüleri modelleme kullanılmaktadır. 2 boyutlu ve 3 boyutlu modellemeler ile gerçekleştirilen FEA'nın karşılaştırılması Tablo 2'de gösterilmektedir (Santos Filho 2009).

Tablo 2. 2D ve 3D oluşturulmuş modellerde FEA'nın karşılaştırılması

\begin{tabular}{|l|l|}
\hline $\begin{array}{l}\text { 2D oluşturulan modellerde } \\
\text { FEA }\end{array}$ & 3D oluşturulan modellerde FEA \\
\hline $\begin{array}{l}\text { Düşük işletme maliyeti } \\
\text { vardır. }\end{array}$ & Daha maliyetlidir. \\
\hline $\begin{array}{l}\text { Daha kısa analiz süresine } \\
\text { sahiptir. }\end{array}$ & Zaman alıcıdır. \\
\hline $\begin{array}{l}\text { Önemli sonuçlar elde } \\
\text { edilebilir ve anında bilgi } \\
\text { sağlayabilir. }\end{array}$ & $\begin{array}{l}\text { Geometrik verilerin oluşturulması ve } \\
\text { model üretilmesi için ek teknolojiler } \\
\text { gerekebilir. }\end{array}$ \\
\hline $\begin{array}{l}\text { Bazı yapısal problemlerin } \\
\text { karmaşıklığı konusunda da } \\
\text { snnırlamalara sahiptir. }\end{array}$ & $\begin{array}{l}\text { Daha gerçekçi stres dağılımları } \\
\text { oluşturma avantajına sahiptir. }\end{array}$ \\
\hline
\end{tabular}

\section{FEA'da kullanılan Malzeme Özellikleri}

Denklemler, FEA ağındaki her öğe için geliştirilir ve tüm sistemin özelliklerini modelleyen bir dizi genel denklemde birleştirilir. Gerekli minimum malzeme özellikleri, poisson oranı ve young katsayısıdır (Saxena ve Chandak 2016).

\section{Sınır koșullarının belirlenmesi}

Sınır koşulları, stres ve yer değiştirmelerin sınır ifadelerini içerir. Nesnenin nerede sabitlendiğini ve kuvvetin nereye uygulandığını gösterir. Nesnenin durumu tarafından belirlenir. Sınır koşulları, analiz edilen nesnenin hangi bölgesine uygulandığına göre belirlenir (Geng ve ark. 2001). Sınır koşullarının seçimi ve uygulanması FEA'nın 
sonucunu etkilemesi bakımından oldukça önemlidir (Soares ve ark. 2012).

\section{2.İşleme aşaması (processing)}

$\mathrm{Bu}$ aşama, bilgisayar yazılımının hesaplama işini yaptığı adımdır (Srirekha ve Bashetty 2010). Kuvvetler uygulandıktan sonra sınırlı sayıda eleman arasında oluşan denklemlerin çözüldüğü ve çözümlendiği aşamadır (Aktı ve Kaya 2020).

\section{3.İşlem sonrası aşaması (post-processing)}

$\mathrm{Bu}$ adım, denklemlerin çözümünün şemalar, şekiller ve renkli grafikler ile görselleştirildiği aşamadır (Siegele ve Soltesz 1989). Üretilen veri miktarı neredeyse sınırsız olmasına rağmen sonuçların kolayca görselleştirilebilmesi önemli bir avantajdır (Soares ve ark. 2012).

\section{Endodontide FEA'nın kullanım alanları ve sonuçları}

\section{Endodontik giriş kavitesinde FEA}

Dişin yapısal bütünlüğü, endodontik tedavi görmüş dişlerin kırılma direncini etkileyen önemli bir faktör olarak kabul edilmiştir (Reeh ve ark. 1989). Endodontik tedavi görmüş dişlerde maksimum diş yapısını ve optimize edilmiş biyomekanik davranışını korumak için minimal invaziv endodonti önerilmiştir (Bürklein ve Schäfer 2015). Minimal invaziv veya ultra konservatif endodontik giriş kavitesi preparasyonları, daha fazla miktarda sağlıklı oklüzal diş yapısını korumak için kullanılmaktadır (Yuan ve ark. 2016).

2018 yılında yapılan bir çalışmada minimal invaziv giriş kavitesi ile tedavi edilen mandibular birinci molar dişlerdeki stres dağılımlarını, geleneksel giriş kaviteleri ile tedavi edilen dişlerle karşılaştırmak için FEA yapılmış ve geleneksel endodontik giriş kavitesinin minimal invaziv giriş kavitesine kıyasla bir dişi kırılmaya daha duyarlı hale getirebileceği bulunmuştur (Allen ve ark. 2018). Yine 2019 yılında çeşitli giriş kavitelerine sahip, endodontik olarak tedavi edilen birinci maksiller molar dişin kırılma direncini tahmin etmek için sonlu elemanlar analizini kullanarak bir çalışma yapılmış ve endodontik tedavi görmüş bir dişin kırılma direncinin, konservatif endodontik kavite hazırlanarak artırılabileceği görülmüştür (Zhang ve ark. 2019).

\section{Kök kanal enstrümantasyonunda FEA}

Farklı preparasyon tekniklerinin kökte meydana getirdiği stres ve kırık olasılıklarını değerlendirmek için çeşitli çalışmalarda FEA kullanılmıştır. FEA'nın kullanıldığ 1 bir çalışmada eğri kanalları olan endodontik tedavi görmüş dişlerde çeşitli yükler altında stres dağılımı incelenmiş ve üç preparasyon tekniği arasındaki farklar belirlenmiştir. Yapılan çalışma sonucunda kullanılan üç farklı preparasyon tekniğinin (crown down, step back, reverse flaring teknikleri) oklüzal yükler ve kondensasyon yükleri uygulandığında FEA modelinin alt kısmında benzer bir stres dağılımı oluşturduğu gösterilmiştir. Ayrıca bu çalışmanın sonuçları sıcak vertikal kondensasyon tekniğinin, aşırı sıkıştırma kuvvetleri uygulandığında kök kırıklarına neden olabileceğini de göstermiştir (Cheng ve ark. 2007; Cheng ve ark. 2009).

Nikel titanyum (NiTi) döner alet eğeleri ve el eğeleri ile gerçekleştirilen kök kanal preparasyonunun kök kırılma duyarlılığı ve kırılma paterni üzerindeki etkilerinin karşılaştırması için yapılan bir çalışmada kırılma duyarlılığı açısından iki preparasyon tekniği arasında anlamlı bir fark bulunamamıştır. Ancak kırık paterni açısından bakıldığında mesio-distal kırık paterninin, döner NiTi grubunda daha sık meydana geldiği görülmüştür (Sathorn ve ark. 2005).

\section{Kök kanal preparasyonundan sonra kök kanal morfolojisinin değerlendirilmesinde FEA}

Vertikal kök kırığı (VRF) önemli bir klinik problemdir. Birkaç çalışma aşırı preparasyon sonucu meydana gelen ince dentinin vertikal kök kırı̆̆ında önemli bir faktör olduğunu kanıtlamıştır (Lertchirakarn ve ark. 2003; Lertchirakarn ve ark. 2003). Ayrıca, iç ve dış kök morfolojisi gibi diğer faktörler, kırılmaya yatkınlığ 1 etkileme potansiyeline sahiptir ve bu nedenler arasında dentin kalınlığı önemli bir faktör olarak kabul edilmektedir (Sathorn ve ark. 2005; Sathorn ve ark. 2005).

Kök kanalı preparasyonundan sonra geometrik parametrelerin diş kırığına göreceli katkısını tartışmak ve dişlerdeki stres dağılımını kantitatif olarak analiz etmek için FEA modelleri oluşturulmuştur. Şimdiye kadar, modifiye edilmiş FEA modellerinde stres dağılımını etkileyen morfolojik parametreler; dentin kalınlığı, kanal kurvatür yarıçapı, kanal kesit şekilleri, kanal düzensizlikleri ve kanal konikliğidir (Hu ve ark. 2010). 


\section{Dentin kalınlı̆̆}

Dentin ne kadar ince olursa, dişin kırılma olasılığ kadar artacaktır (Wilcox ve ark. 1997). Dentin kalınlığının kırık duyarlılığına etkisini incelemek için bir çalışma planlanmış ve kanal çapları kademeli olarak arttırılarak FEA modelleri oluşturulmuştur. Yapılan bu çalışma sonucunda kanal çapları arttıkça, kavramsal kırılma yükünün buna göre daha düşük olduğu ve dentin ne kadar çok çıkarılırsa kırılma duyarlılığının o kadar artacağı görülmüştür (Sathorn ve ark. 2005). Dentin kalınlığı üzerinde yapılan başka bir çalışma ise orta derecede bir kanal preparasyonu yapıldığında, dentin kalınlığının kırık bölgesi veya yönünde belirleyici bir faktör olmadığını göstermektedir (Lertchirakarn ve ark. 2003).

\section{Kanal kurvatür yarıçapı}

Kurvatür yarıçapı, belirli bir kurvatür açısının kanal düz bir çizgiden saparken ne kadar ani veya ciddi şekilde oluştuğunu gösterir. Kurvatür yarıçapı ne kadar küçükse, kanal sapması o kadar ani olur (Ibrahim ve ark. 2017). Klinikte kurvatürlü birkanala yapılacak kanal tedavisiönemli bir sorundur çünkü özellikle preparasyon sırasında kanal şeklinde istenmeyen değişikliklerin meydana gelmesine neden olabilir. Gerçekleştirilen kanal preparasyonu kök kanalının bazı kısımlarında ince dentin kalmasına neden olursa, vertikal kök kırığı meydana gelebilir (Cheng ve ark. 2007).

Farklı şekilli kök kanallarına yapılan kök kanal preparasyonu sırasında döner endodontik aletlerin mekanik davranışları hakkında bilgi edinmek için bir çalışma yapılmış ve kurvatür yarıçapının ve konumunun, cihazdaki stresi belirleyen en önemli parametreler olduğu, yarıçap1 azaltarak ve apikalden orta kök konumuna hareket ederek daha yüksek stres seviyelerinin üretildiği gösterilmiştir. $\mathrm{Ni}$-Ti aletler için en zorlu çalışma koşullarının, özellikle cihazların daha büyük çaplara sahip olduğu alanlarda, keskin kurvatürlere sahip kanallarda olduğu gözlenmiştir. $\mathrm{Bu}$ çalışmanın sonuçlarına göre aletlerde olası hasarı ve kırılmayı önlemek için eğelerin bu tür kanallarda kullanıldıktan sonra atılması tavsiye edilmektedir (Necchi ve ark. 2008).

\section{Kanal kesit şekilleri ve kanal düzensizlikleri}

Vertikal kök kırığının oluşmasına neden olan pek çok değişken klinisyenin kontrolü dışında olsa da (doğal kök morfolojisi, kanal şekli ve boyutu, dentin kalınlığı), kırık duyarlılığını azaltmak için tedavi esnasında bazı hususlara dikkat etmek gerekir. Bu hususlar arasında son kanal şekli, kanal genişletmesinin miktarı ve stres konsantrasyon bölgeleri olarak işlev gören düzensizliklerin ortadan kaldırılması yer alır. Bununla birlikte, kanal duvarındaki düzensizliklerin ortadan kaldırılması ve kanal boyunca pürüzsüz, yuvarlak bir kanal şeklinin oluşturulması, daha düzgün bir gerilim dağılımı ve daha düşük gerilmelerle sonuçlanmaktadır. $\mathrm{Bu}$ nedenle dentinin çıkarılması her zaman kırılma duyarlılığının artması ile sonuçlanmaz. Şerit şeklindeki kanalların bukkal ve lingual sonlanmalarında olduğu gibi stres artırıcı alanların ortadan kaldırılması, onu kırılmaya karşı daha az duyarlı hale getirir (Sathorn ve ark. 2005).

Kontrollü konisiteye sahip nikel-titanyum döner aletlerle yapılan kanal preparasyonunun kök içinde daha düzgün gerilim dağılımlarına yol açıp açmadığını ve böylece kırılma duyarlılığını azaltıp azaltmadığını incelemek için FEA'nın kullanıldığı bir çalışma yapılmıştır. Çalışma sonucunda en büyük gerilmelerin kanal duvarında meydana geldiği ve oval kanalların bukkal ve lingual uzantılarında yüksek stres konsantrasyonlarına neden olduğu görülmüştür. Yuvarlak kanal profilleri ve düzgün kanal konikliğinin elde edilmesinin bir sonucu olarak kırık duyarlılı̆̆ında azalma görülmüştür. Kök içindeki gerilimlerin daha düşük olduğu ve gerilimlerin preparasyon öncesine göre daha eşit bir şekilde dağıldığı görülmüştür (Versluis ve ark. 2006).

\section{Kanal konikliği}

Vertikal kök kırığı eğilimini etkileyebilecek potansiyel faktörlerden birisi de hazırlanan kanal çapıdır. Genel olarak, koniklik, doldurma sırasında spreaderların veya pluggerların derinlemesine nüfuz etmesine izin verecek kadar yeterli olmalı, ancak prosedürel hatalarının meydana gelebileceği ve kökü gereksiz yere zayıflatacak kadar aşırı olmamalıdır (Walton ve Torabinejad 1996).

Değişen kanal konisitesinin kökte meydana getirdiği gerilmeleri ve dolayısıyla vertikal kök kırığı üzerindeki etkisini incelemek için FEA kullanılarak yapılan çalışmada, kanallar sıcak vertikal kondensasyon tekniği ile doldurulmuş, farklı konisitelerin kök üzerinde oluşturduğu etki hesaplanmıştır. Yapılan bu çalışma sonucunda artan koniklik ile, kök kanal dolgusu esnasında kökte meydana gelen gerilmelerin azaldığı, ancak çiğneme yüklemesi ile oluşan gerilmelerin artma eğilimi gösterdiği bulunmuştur. 
Ayrıca bu çalışmadan elde edilen sonuçlar; kökün apikal üçte birinde meydana gelen kök kırı̆̆ının kök kanal dolumu esnasında başlarken, servikal kısımda meydana gelen kök kırığının ise oklüzal yükler nedeniyle meydana geldiğini göstermektedir (Rundquist ve Versluis 2006). Sonlu eleman analizini kullanarak yapılan başka bir çalışmada, üretilen radiküler gerilimlerin büyüklüğünün, simüle edilmiş kanal çapları ile doğrudan ilişkili olduğu bulunmuştur (RicksWilliamson ve ark. 1995).

\section{Dış kök morfolojisi}

Kanal kesit şekli, kök kesit şekli ve dentin kalınlığının kırılma duyarlılığını ne ölçüde etkilediğini belirlemek için bir çalışma planlanmış ve belirlenen parametreler değiştirilerek bir dizi FEA modeli oluşturulmuştur. Sonlu eleman modelleri, stres konsantrasyonu açısından kanal kurvatürünün dış kök morfolojisinden daha önemli olduğunu göstermiştir. Yapılan çalışma sonucunda yuvarlak kanal şeklinin, oval kanal şeklindekinden daha fazla kırılma direncine sahip olduğu kanıtlanmıştır. Ayrıca kanal şekli, stres dağılımında kök şekline göre daha önemli değişikliklere neden olmuştur (Lertchirakarn ve ark. 2003).

\section{Nikel-Titanyum Döner Aletler ve FEA}

Endodontide kök kanal tedavisi için Nikel-Titanyum (NiTi) döner alet eğelerinin kullanımının artmasıyla, alet kırı̆̆ı giderek daha yaygın hale gelmiştir. Alet kırılması, klinik uygulamada istenmeyen bir durumdur ve döner aletler kullanırken oluşan en önemli endişelerden biridir (Yared ve ark. 2002). NiTi döner aletlerin fiziksel özellikleri ve mekanik özellikleri hakkında çeşitli araştırmalar yapılmıştır.

Beş farklı NiTi döner alet eğesinin ( 3 tane 1 sıl işlem görmüş NiTi eğe, iki tane konvansiyonel NiTi eğe) mekanik rotasyonu sırasında kök dentin kanalında oluşan gerilim dağılımını hesaplamak için bir çalışma tasarlanmıştır. Yapılan bu çalışma sonucunda konvansiyonel NiTi alaşıma sahip eğelerin kurvatürlü alanda diğer cihazlara kıyasla daha yüksek gerilim değerleri gösterdiği bulunmuştur. Ayrıca kanal dentininin elastik modülü ve alet konikliği ve tasarımına bakılmaksızın kullanılan eğelerin en stresli bölgesinin, kurvatürlü bölgede olduğu görülmüştür (Prati ve ark. 2021). Diğer bir çalışmada ise metalurjik olarak farklı iki eğe (ProTaper Next, HyFlex CM) ile enstrümantasyon sırasında kök kanal duvarlarında meydana gelen gerilme miktarı, farklı yarıçaplara sahip hassas kök modellerinde incelenmiştir. $\mathrm{Bu}$ çalışmanın sonuçlarına göre kurvatür yarıçapının, gerilim miktarı ve dolayısıyla bir aletin yorulma ömrü üzerinde açık bir etkiye sahip olduğu görülmüştür. Ayrıca kök kanal hazırlığını takiben kök kanal dentinindeki gerilim miktarının, aletin özelliklerine ve geometrisine bağlı olduğu, ancak stres dağılımının hangi alet kullanılırsa kullanılsın benzer olduğu görülmüştür (Ibrahim ve ark. 2017).

\section{Kök kanal dolgusunun kondensasyonunda FEA}

Vertikal ve lateral kondensasyon sırasında kök kanal duvarında meydana gelen gerilme değişimlerini analiz etmek için bir çalışma yapılmış ve vertikal kondensasyon nedeniyle kök kanal duvarında meydana gelen gerilmenin, aynı yükleme koşulları altında lateral kondensasyon nedeniyle meydana gelen gerilmeden daha yüksek olduğu sonucuna ulaş̧lmıştır. Ayrıca yazarlar, lateral kondensasyonun doğrudan vertikal kök kırığına neden olmayacağını, ancak kullanılan her iki yöntemde de aşırı kuvvet ve yanlış uygulamaların tehlikeli olduğunu ve bu durumların vertikal kök kırığına neden olabileceğini vurgulamışlardır (Hong ve ark. 2003).

Bir maksiller kanin diş modelinde Sistem B 1S1 obturasyon tekniği simülasyonu sırasında, dişi çevreleyen periodontal dokularda ve kemiklerde sıcaklık dağılımını ve seviyesini belirlemek için bir çalışma tasarlanmıştır. Yapılan bu çalışma sonucunda yazarlar Sistem B tekniği simülasyonunun potansiyel olarak zararlı sicaklık seviyeleri yaratmadığı sonucuna varmışlardır (Er ve ark. 2007).

\section{Post ve core restorasyonlar için FEA}

Geniş çapta kron yapısı kaybına uğramış endodontik tedavi görmüş bir dişte koronal restorasyonu korumak için post sistemleri kullanılmaktadır (Schwartz ve Robbins 2004). FEA kullanılan bir çalışmada fiber ve metal postların endodontal-periodontal lezyonlu premolar dişlerde stres dağılımı üzerindeki etkisi test edilmiş ve metal postların stresi gövdede tuttuğu, periodontal dokulara daha az stres ilettiği sonucuna ulaşılmıştır. Yapılan bu çalışmanın sonucuna göre endodontal-periodontal lezyonların dişlerdeki stres dağılımı üzerinde etkisi olduğu için post materyal seçiminin lezyonun ciddiyetine göre yapılması gerektiği görülmüştür (Belli ve ark. 2017).

Farkl1 prefabrike postlarla restore edilmiş, endodontik tedavi görmüş maksiller santral kesici dişler üzerindeki gerilim dağılımını değerlendirmek için sonlu elemanlar 
analizi kullanılarak başka bir çalışma planlanmıştır. Yapılan çalışmanın sonuçları fiber postların, metal postlardan daha homojen stres dağılımı gösterdiği ve post materyalinin, endodontik tedavi görmüş dişlerdeki stres dağılımı için postun dış konfigürasyonundan daha etkili olduğunu göstermiştir (Silva ve ark. 2009).

\section{Kalsiyum silikat esaslı materyallerin araştırılmasında FEA}

Vital pulpa tedavilerinde, kuafaj materyallerinin basınç dayanımı kapasitesi önemli bir fiziksel özellik olarak kabul edilir. Pulpa perforasyonları üzerine yerleştirilen mineral trioksit agregat (MTA) üzerine yapılacak kompozit restorasyan sırasında, MTA üzerinde meydana gelen gerilme dağılımını değerlendirmek için bir çalışma tasarlanmıştır. $\mathrm{Bu}$ çalışmada farklı genişlikteki pulpa perforasyonları farklı kalınlıktaki MTA ile doldurulmuş ve toplam 9 farklı model oluşturulmuştur. Elde edilen sonuçlara göre MTApulpa arayüzündeki gerilmelerin ve MTA üzerindeki gerilimin, MTA kalınlığındaki artışla azaldığı görülmüştür. $\mathrm{Bu}$ çalışmadan elde edilen sonuçlar doğrultusunda MTA uygularken MTA'nın üzerine uygulanacak kondensasyon yüklerine dayanabilmesi için en az 2-3 mm kalınlığında uygulanması gerektiği bildirilmiştir (Ozkurt-Kayahan ve ark. 2020).

İnternal kök rezorpsiyonu olan dişlerde kök kanallarının doldurulması için kullanılan MTA ve gutta perkanın dişlerde stres dağılımını ne ölçüde etkilediğini belirlemek için bir çalışma planlanmıştır. Yapılan bu çalışma MTA kullanımının, rezorpsiyon bölgelerinde stres konsantrasyonu riskini azalttığı, gutta-perka kullanılarak yapılan kök kanalı dolgularının ise stresi dentin dokusuna aktardığı için kırık riskini arttırdığını göstermiştir. Yine bu çalışmanın bulgularına göre hem MTA hem de MTA ve gütaperka kombinasyonunun, internal kök rezorpsiyonu olan dişlerde kanalların doldurulması için klinik pratiğinde kullanılması önerilmiştir (Aslan ve ark. 2019).

Mandibular molar dişlerdeki çeşitli iyatrojenik kök perforasyonlarının Biodentine ve MTA ile onarımı sonrası gerilim dağılımını değerlendirmek için bir çalışma yapılmıştır. Yapılan çalışmanın sonuçları, Biodentine modellerinin MTA modellerinden daha düşük maksimum von Mises gerilim değerleri gösterdiğini ve strip perforasyonların kök perforasyon bölgelerinde furkasyon perforasyonu ve post boşluğu oluşturulması esnasında oluşan perforasyonlara göre daha yüksek strese maruz kaldığını göstermiştir. Ayrıca bu çalışmada MTA ve
Biodentine kullanımının, kök perforasyon bölgelerinde potansiyel olarak zararlı stres riskini azaltabileceğini de gösterilmiştir (Aslan ve ark. 2021).

\section{Endodontik tedavi yapılan dişlerin restoratif prosedürlerinin değerlendirilmesinde FEA}

Endodontik tedaviden sonra dişlerin kırılma direncinin azaldığı bilinir ve fonksiyonel kuvvetler karşısında diş dokularındaki stres miktarı artar (Yıkılgan ve Bala 2013). Yapılan tedavinin klinik olarak başarılı olması için, endodontik tedaviden sonra yapılan restorasyonun tedavi sırasında yapılan uygulamalar kadar önemli olduğu vurgulanmaktadır. Yapılan birçok çalışma endodontik olarak tedavi edilen dişe yapılan restorasyon kalitesi ile endodontik tedavinin başarısı arasında doğrudan bir ilişki olduğunu ileri sürmektedir (Kirkevang ve ark. 2000; Tronstad ve ark. 2000).

Yakın zaman önce yapılan bir çalışmada rezin kompozit ile restore edilen kanal dolgulu dişlerde oblik ve vertikal kuvvetler ile oluşan gerilmeleri analiz etmek için sonlu elemanlar analizi kullanılmış ve restoratif tekniklerin ve farklı kaide materyallerinin kullanımının stres oluşumu üzerindeki etkileri incelenmiş̧ir. Tüm modellerde, oblik kuvvetlerin vertikal kuvvetlerden daha fazla stres yarattığ görülmüştür. Endodontik tedaviden sonra dişlere yapılan kasp kapatma, fonksiyonel kasp kapatma ve dokuma fiber kullanımı gibi restoratif yaklaşımların, diş üzerindeki stres oluşumunu etkilemediği sonucuna varılmıştır (Yıkılgan ve Bala 2013).

Endokuron ve post-core ile restore edilen aşırı koronal doku kaybı olan endodontik tedavi görmüş azı dişlerinin köklerinde meydana gelen gerilmeleri değerlendirmek için bir çalışma yapılmıştır. Endokuronların, geleneksel post-core ve kurona kıyasla kök kanalı iç duvarında stres konsantrasyonunu azalttığı görülmüştür. Yapılan bu çalışmada endokuron ile restore edilen azı dişlerinin, postcore ile restore edilen dişlere kıyasla kök kırığına daha az meyilli olduğu sonucuna ulaşılmıştır (Lin ve ark. 2020).

\section{SONUÇ}

Diş hekimliğinin çeşitli uzmanlık alanlarında, sonlu elemanlar stres analizinin uygulamaları vardır ve bu yöntem endodonti alanında da siklıkla kullanılmaktadır. Sonlu elemanlar analizi kullanılarak yapılan deneylerin kolaylıkla tekrarlanabilir olması ve çalışma tasarımlarının 
gereksinime göre modifiye edilip değiştirilebilmesi gibi avantajları nedeniyle FEA kullanışlı bir yöntemdir. FEA'dan objektif bir sonuç elde etmek için dişlerin gerçek yapısının simüle edilebilmesi hala bir zorluk teşkil etmektedir. Sonlu elemanlar analizinin sinırlamaları göz önünde bulundurulmalı ve bu yöntem deneysel araştırmalardan daha az zaman alıcı olsa da deneysel analizlerin yerine tek başına kullanılmamalı ve deneysel yöntemlerle desteklenmelidir.

\section{KAYNAKLAR}

1. Aktı A, Kaya DI. Finite Element Analysis and Application in Dental Implantology. Int J Innov Sci Res Technol. 2020; 5(2): 423-7.

2. Allen C, Meyer CA, Yoo E, Vargas JA, Liu Y, Jalali P. Stress distribution in a tooth treated through minimally invasive access compared to one treated through traditional access: A finite element analysis study. J Conserv Dent: JCD. 2018; 21(5): 505-9.

3. Aslan T, Esim E, Üstün Y, Dönmez Özkan H. Evaluation of Stress Distributions in Mandibular Molar Teeth with Different Iatrogenic Root Perforations Repaired with Biodentine or Mineral Trioxide Aggregate: A Finite Element Analysis Study. J Endod. 2021; 47(4): 631-40.

4. Aslan T, Üstün Y, Esim E. Stress distributions in internal resorption cavities restored with different materials at different root levels: A finite element analysis study. Aust Endod J. 2019; 45(1): 64-71.

5. Belli S, Eraslan O, Hakki SS, Eskitascioglu M, Eskitascioglu G. Effect of post-restoration on stresses in premolars with endodontic-periodontal lesion: an FEA study. J Adhes Sci Technol. 2017; 31(6): 591-601.

6. Bürklein S, Schäfer E. Minimally invasive endodontics. Quintessence Int. 2015; 46(2): 119-24.

7. Cheng R, Zhou X-D, Liu Z, Hu T. Development of a finite element analysis model with curved canal and stress analysis. J Endod. 2007; 33(6): 727-31.

8. Cheng R, Zhou XD, Liu Z, Yang H, Gao QH, Hu T. Finite element analysis of the effects of three preparation techniques on stresses within roots having curved canals. Int Endod J. 2009; 42(3): 220-6.

9. Craig R, Powers J. Restorative dental materials 11th ed. St. Louis: Mosby. 2002: 238-92.

10. Çalıkoğlu S. Bölümlü Protezler, 2. Bask1, İstanbul Ü Basımevi, İstanbul. 1992.

11. De Vree J, Peters M, Plasschaert A. A comparison of photoelastic and finite element stress analysis in restored tooth structures. J Oral Rehabil. 1983; 10(6): 505-17.

12. Desai SR, Shinde HH. Finite Element Analysis: Basics And Its Applications In Dentistry. Indian J Dent Sci. 2012; 4(1): 60-5.

13. Er Ö, Yaman SD, Hasan M. Finite element analysis of the effects of thermal obturation in maxillary canine teeth. Oral Surg Oral Med Oral Pathol Oral Radiol Endod. 2007; 104(2): 277-86.
14. Farah J, Craig R. Finite element stress analysis of a restored axisymmetric first molar. J Dent Res. 1974; 53(4): 859-66.

15. Fung Y-c. Biomechanics: mechanical properties of living tissues: Springer Science \& Business Media; 2013

16. Gao J, Xu W, Ding Z. 3D finite element mesh generation of complicated tooth model based on CT slices. Comput Methods Programs Biomed. 2006; 82(2): 97-105.

17. Geng J-P, Tan KB, Liu G-R. Application of finite element analysis in implant dentistry: a review of the literature. $\mathrm{J}$ Prosthet Dent. 2001; 85(6): 585-98.

18. Gokhale N, Deshpande S, Bedekar S, Thite A. Practical finite element analysis: Finite to infinite; 2008

19. Hammond D, Whitty J. Finite element analysis and dentistry. Fac Dent J. 2015; 6(3): 134-9.

20. Hong J, Xia WW, Xiong HG. [Analysis of the effect on the stress of root canal wall by vertical and lateral condensation procedures]. Shanghai Kou Qiang Yi Xue. 2003; 12(5): 35961.

21. Hu T, Cheng R, Shao M et al. Application of finite element analysis in root canal therapy. Finite Element Analysis. 2010: 103: 99-120.

22. Huempfner-Hierl H, Schaller A, Hemprich A, Hierl T. Biomechanical investigation of naso-orbitoethmoid trauma by finite element analysis. Br J Oral Maxillofac Surg. 2014; 52(9): 850-3.

23. Ibrahim AA, El Ashry SH, Fayyad DM. Stress Analysis of Two Ni-Ti Rotary Files in Simulated Root Canals Using Finite Element Method-Part II: Root Analysis. Egypt Dent J. 2017; 63: 841-8.

24. Kirkevang LL, Ørstavik D, Hörsted $\square$ Bindslev P, Wenzel A. Periapical status and quality of root fillings and coronal restorations in a Danish population. Int Endod J. 2000; 33(6): 509-15.

25. Küçükkurt S. Sonlu Elemanlar Stres Analiz Yöntemi ve Dental İmplantoloji Alanında Yapılan Araştırmalar. J Dent Fac Atatürk Uni. 2019; 29(4): 701-10.

26. Lertchirakarn V, Palamara JE, Messer HH. Finite element analysis and strain-gauge studies of vertical root fracture. J Endod. 2003; 29(8): 529-34.

27. Lertchirakarn V, Palamara JE, Messer HH. Patterns of vertical root fracture: factors affecting stress distribution in the root canal. J Endod. 2003; 29(8): 523-8.

28. Lin J, Lin Z, Zheng Z. Effect of different restorative crown design and materials on stress distribution in endodontically treated molars: a finite element analysis study. BMC Oral Health. 2020; 20(1): 1-8.

29. Magne P. Efficient 3D finite element analysis of dental restorative procedures using micro-CT data. Dent Mater. 2007; 23(5): 539-48.

30. Marghitu DB. Mechanical engineer's handbook: Elsevier; 2001

31. Necchi S, Taschieri S, Petrini L, Migliavacca F. Mechanical behaviour of nickel $\square$ titanium rotary endodontic instruments in simulated clinical conditions: a computational study. Int Endod J. 2008; 41(11): 939-49.

32. Ozkurt-Kayahan Z, Turgut B, Akin H, Kayahan MB, Kazazoglu E. A 3D finite element analysis of stress 
distribution on different thicknesses of mineral trioxide aggregate applied on various sizes of pulp perforation. Clin Oral Investig. 2020; 24(10): 3477-83.

33. Poiate IA, Vasconcellos AB, Mori M, Poiate $\mathrm{Jr}$ E. 2D and 3D finite element analysis of central incisor generated by computerized tomography. Comput Methods Programs Biomed. 2011; 104(2): 292-9.

34. Prati C, Mendes Tribst JP, Piva AMdOD et al. 3D Finite Element Analysis of Rotary Instruments in Root Canal Dentine with Different Elastic Moduli. Appl. Sci. 2021; 11(6): 1-14.

35. Reeh ES, Messer HH, Douglas WH. Reduction in tooth stiffness as a result of endodontic and restorative procedures. J Endod. 1989; 15(11): 512-6.

36. Rho JY, Ashman RB, Turner CH. Young's modulus of trabecular and cortical bone material: ultrasonic and microtensile measurements. J Biomech. 1993; 26(2): 111-9.

37. Ricks-Williamson LJ, Fotos PG, Goel VK, Spivey JD, Rivera EM, Khera SC. A three-dimensional finite-element stress analysis of an endodontically prepared maxillary central incisor. J Endod. 1995; 21(7): 362-7.

38. Romeed S, Fok S, Wilson N. Finite element analysis of fixed partial denture replacement. J Oral Rehabil. 2004; 31(12): 1208-17.

39. Rundquist BD, Versluis A. How does canal taper affect root stresses? Int Endod J. 2006; 39(3): 226-37.

40. Sakaguchi RL, Powers JM. Craig's restorative dental materials-e-book: Elsevier Health Sciences; 2012

41. Santos Filho PCdF. Biodinamica restauradora de dentes tratados endodonticamente: analise por elementos finitos. Piracicaba: Faculdade de Odontologia da Universidade Estadual de Campinas. 2009.

42. Sathorn C, Palamara JE, Messer HH. A comparison of the effects of two canal preparation techniques on root fracture susceptibility and fracture pattern. J Endod. 2005; 31(4): 283-7.

43. Sathorn C, Palamara JE, Palamara D, Messer HH. Effect of root canal size and external root surface morphology on fracture susceptibility and pattern: a finite element analysis. J Endod. 2005; 31(4): 288-92.

44. Saxena A, Chandak M. Finite Element Analysis (FEA) as a Decisive Tool for Study of Force Distribution in Dentistry. Sch J Dent Sci. 2016.

45. Schwartz RS, Robbins JW. Post placement and restoration of endodontically treated teeth: a literature review. J Endod. 2004; 30(5): 289-301.

46. Shetty P, Hegde AM, Rai K. Finite element method-an effective research tool for dentistry. J Clin Pediatr Dent. 2010; 34(3): 281-5.

47. Siegele D, Soltesz U. Numerical investigations of the influence of implant shape on stress distribution in the jaw bone. Int J Oral Maxillofac Implants. 1989; 4(4): 333-40.
48. Silva NR, Castro CG, Santos-Filho PC et al. Influence of different post design and composition on stress distribution in maxillary central incisor: Finite element analysis. Indian J Dent Res. 2009; 20(2): 153-8.

49. Soares CJ, Versluis A, Valdivia A et al. Finite element analysis in dentistry-Improving the quality of oral health care. Moratal D. Finite element analysis-from biomedical applications to industrial developments. Rijeka: In Tech Croatia. 2012: 25-56.

50. Srirekha A, Bashetty K. Infinite to finite: an overview of finite element analysis. Indian J Dent Res. 2010; 21(3): 42532.

51. Sung SJ, Baik HS, Moon YS, Yu HS, Cho YS. A comparative evaluation of different compensating curves in the lingual and labial techniques using 3D FEM. Am J Orthod Dentofacial Orthop. 2003; 123(4): 441-50.

52. Thresher RW, Saito GE. The stress analysis of human teeth. Journal of biomechanics. 1973; 6(5): 443-9.

53. Tronstad L, Asbjørnsen K, Døving L, Pedersen I, Eriksen H. Influence of coronal restorations on the periapical health of endodontically treated teeth. Dent Traumatol. 2000; 16(5): 218-21.

54. Verdonschot N, Fennis WM, Kuijs RH, Stolk J, Kreulen $\mathrm{CM}$, Creugers NH. Generation of 3-D finite element models of restored human teeth using micro-CT techniques. Int $\mathrm{J}$ Prosthodont. 2001; 14(4): 310-5.

55. Versluis A, Messer H, Pintado M. Changes in compaction stress distributions in roots resulting from canal preparation. Int Endod J. 2006; 39(12): 931-9.

56. Versluis A, Tantbirojn D. Relationship between shrinkage and stress. Dental computing and applications: advanced techniques for clinical dentistry. IGI Global,2009. pp. 45-64.

57. Walton RE, Torabinejad M. Principles and Practice of Endodontics, Philadelphia: W.B. Saunders; 1996

58. Wilcox LR, Roskelley C, Sutton T. The relationship of root canal enlargement to finger-spreader induced vertical root fracture. J Endod. 1997; 23(8): 533-4.

59. Yared GM, Dagher FE, Machtou P, Kulkarni GK. Influence of rotational speed, torque and operator proficiency on failure of Greater Taper files. Int Endod J. 2002; 35(1): 7-12.

60. Yikılgan I, Bala O. How can stress be controlled in endodontically treated teeth? A 3D finite element analysis. ScientificWorldJournal. 2013; 2013: 1-7.

61. Yuan K, Niu C, Xie Q et al. Comparative evaluation of the impact of minimally invasive preparation vs. conventional straight-line preparation on tooth biomechanics: a finite element analysis. Eur J Oral Sci. 2016; 124(6): 591-6.

62. Zhang Y, Liu Y, She Y, Liang Y, Xu F, Fang C. The Effect of Endodontic Access Cavities on Fracture Resistance of First Maxillary Molar Using the Extended Finite Element Method. J Endod. 2019; 45(3): 316-21. 